\title{
Biosimilar Products in the Modern U.S. Health Care and Regulatory Landscape
}

\author{
Jesse Peterson, PharmD, MS; Holly Budlong, PharmD, PhD; Tim Affeldt, PharmD; \\ Kyle Skiermont, PharmD; Gregg Kyllo, MS, RPh; and Al Heaton, PharmD
}

\begin{abstract}
SUMMARY
Biosimilars have the potential to greatly reduce medication costs in the United States. As of July 1, 2017, 5 biosimilars have been approved by the FDA, but only 2 are available for purchase. This commentary outlines the efforts of an integrated health system to ensure biosimilar accessibility and discusses the current challenges and future implications. We highlight the implementation of a health plan policy and how a health system's formulary committee can encourage use while considering provider perceptions and operational challenges. In addition, we provide our perspective on potential implications for pricing, site of care, and pharmacy dispensing practices based on our experience with regulatory hurdles and market trends. Overall, we believe biosimilars are a good thing for the health care system, but their expected benefit may not be realized for years to come.
\end{abstract}

J Manag Care Spec Pharm. 2017;23(12):1255-59

Copyright $\odot 2017$, Academy of Managed Care Pharmacy. All rights reserved.

$\mathrm{F}$ ederal law establishes the pathway for new drug approvals, while individual states regulate the day-to-day practice of pharmacy. According to the U.S. Food and Drug Administration (FDA), a biologic is a large complex molecule that is derived from living sources and is more difficult to characterize and manufacture than traditional small molecule products such as aspirin. ${ }^{1}$ Biologic products are anywhere from 200 to 1,000 times the size of traditional small molecule pharmaceuticals and, because of their large size, require nearly 5 times as many tests to ensure their potency and purity. ${ }^{2}$ In addition to their large size, biologic products are highly sensitive to temperature and $\mathrm{pH}$, which put their structure and stability at risk. ${ }^{2}$ Minor changes in the manufacturing process could have a major impact on the safety, efficacy, and stability of a biologic product. This impact can manifest as batch-tobatch variation in the production of reference biologics that currently exist in the marketplace. ${ }^{3}$

A biosimilar is a biologic medicine that is highly similar to a reference biologic, but unlike generic small molecule products, which have identical active ingredients to their reference product, biosimilars are not identical. ${ }^{3}$ The FDA defines a biosimilar product as a biologic that is highly similar to the reference biologic product with no clinically meaningful differences in terms of safety, purity, and potency. ${ }^{1}$ Biosimilar products cannot be readily substituted for brand-name reference biologic products unless state legislation has deemed it appropriate. With the current legislation in Minnesota, where our health system is located, substitution can only occur if a biosimilar is classified as an interchangeable biologic, which the FDA defines as a biosimilar that meets additional standards for interchangeability. ${ }^{1,4}$ As of June 30, 2017, a draft guidance for interchangeability criteria has been released, and the FDA is currently reviewing comments received from the public before publishing a final guidance.

\section{Approval Pathway}

To better understand biologics, it is important to appreciate the FDA's current drug application processes (Figure 1). Small molecule products are approved via a New Drug Application (NDA), or the 505(b) application, which requires the manufacturer (MFG) to generate a report on the safety and efficacy of its product in order to achieve approval. ${ }^{5}$ To manufacture, market, and distribute a generic small molecule product, an Abbreviated New Drug Application (ANDA), or 505(j) application, must be submitted, in which the MFG must demonstrate bioequivalence to get a product approved. ${ }^{5}$

A new biologic product requires a 351(a) Biologic License Application (BLA), which is analogous to the NDA for small molecules. However, for biosimilars, a 351(k) BLA is required, which is more complicated than the ANDA process for generic small molecule products. The $351(\mathrm{k})$ BLA requires the MFG to prove that its biosimilar product is highly similar to the reference product with no clinically meaningful differences. ${ }^{7}$ Approval can be granted for indications that were previously assigned to the reference product; however, the applicant can seek fewer routes of administration, which could result in fewer FDA-approved indications. ${ }^{6}$ The $351(\mathrm{k})$ BLA will ultimately specify additional criteria required by the FDA to achieve an interchangeable designation.

Before the existence of a biosimilar application process, there were cases in which there were no reference biologics (i.e., no 351(a) BLA on file because the application did not exist), and the MFG was required to submit a 505(b)(2) application. ${ }^{7}$ This alternative application has been used with insulin (Basaglar) and the human growth hormone (Omnitrope); these products are referred to as follow-on biologics, and these 2 particular products are not interchangeable. ${ }^{7-9}$ To further complicate the understanding of the process, there has also been a successful filing using the 351(a) application for an additional 
Small Molecule Drug

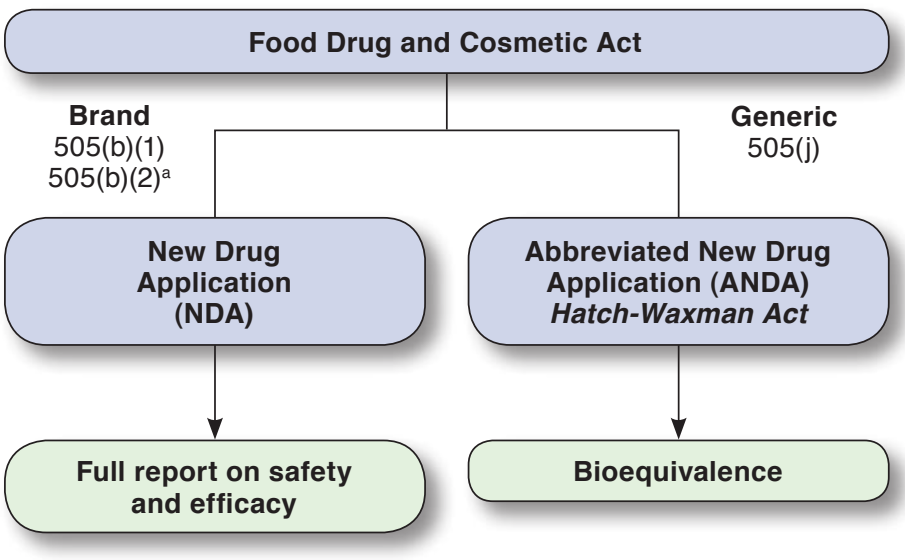

Biologic

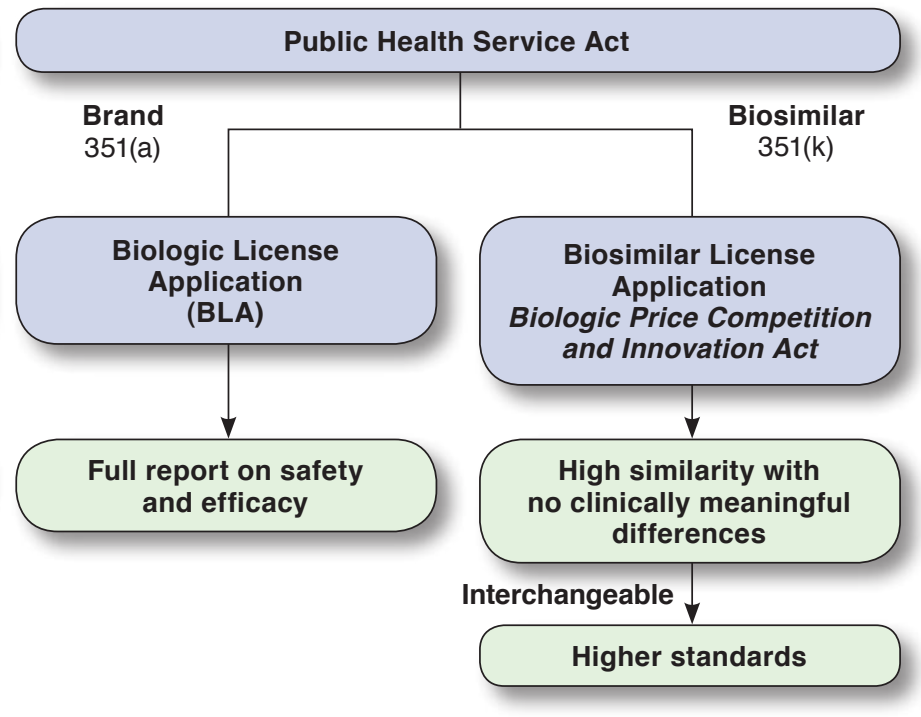

Adapted from QuintilesIMS. Biosimilars by region: United States. Regulatory guidelines in the United States. ${ }^{25}$

aThe 505(b) (2) application for a new drug relies, at least in part, on data not developed by the applicant.

filgrastim product. Granix (tbo-filgrastim), a product with 1 FDA-approved indication, filed its application before the 351(k) application was available and, as a result, did not depend on any Neupogen (filgrastim) clinical trial data. ${ }^{10}$

\section{Naming Conventions}

There have been 5 biosimilars approved by the FDA, but as of July 1, 2017, only 2 are on the market (Table 1). ${ }^{11-20}$ As seen in Table 1, each biosimilar has a new trade name and an International Nonproprietary Name (INN), commonly referred to as the generic name. In addition, each biosimilar name is hyphenated with a 4-letter suffix. This suffix was recommended in a guidance document released by the FDA to help minimize inadvertent substitution and facilitate pharmacovigilance (postmarketing surveillance) ${ }^{21}$

Use of a suffix is a key difference in how biosimilars have rolled out globally. The European Medicines Agency (EMA) has had a biosimilar pathway in place since 2006, and in Europe, there are currently more than 20 products on the market. ${ }^{22}$ The EMA has allowed manufacturers to use a trade name and an INN that corresponds to the reference product without an additional suffix. ${ }^{22}$ In the United States, Neupogen is the reference biologic product and filgrastim is the established INN (or generic name) for that product. The first biosimilar approved in the United States was Zarxio, and although it is a biosimilar to Neupogen, its generic name is filgrastim-sndz. The INN for the 2 products are not the same, since the biosimilar name contains the additional 4-letter suffix. In Europe, where the reference biologic and biosimilar have different brand names (Neupogen and Zarzio-spelled differently in Europe) but have the same INN. This difference is important because name recognition can affect how products gain market penetration and could negatively affect patient and provider perceptions. The 4-letter suffix and unique trade name make it more difficult to associate the reference biologic to the biosimilar product.

\section{Pricing Considerations}

The creation of a biosimilar approval pathway was meant to facilitate bringing biosimilars to market in order to increase competition and control prices. A 2013 report estimated that the United States would save $\$ 250$ billion between 2014 and 2024 if the 11 most likely biosimilars were to enter the marketplace. ${ }^{23}$ Table 1 includes an average wholesale price (AWP) per unit comparison as of June 30, 2017. The AWP is the sticker price, which is not typically the price paid, but it provides a frame of reference for the discounts that have been seen thus far. As of June 30, 2017, both approved biosimilar products have offered less than 20\% off the list price of the branded products. With only 2 approved products on the market, increased competition and lower prices have not yet been realized. We expect that prices will decrease over time as more biosimilar products enter the market in these therapeutic categories. 
Biosimilar Products in the Modern U.S. Health Care and Regulatory Landscape

TABLE 1 Biosimilars, Follow-on Biologics, and New Biologics Modeling Existing Products 11-20

\begin{tabular}{|c|c|c|c|c|c|}
\hline Biosimilars & Reference Products & $\begin{array}{l}\text { Application } \\
\text { Process }\end{array}$ & Approved & Launch & $\begin{array}{c}\text { AWP Unit Price } \\
\text { Comparison }\end{array}$ \\
\hline Zarxio 300 mcg (filgrastim-sndz) & Neupogen (filgrastim) & $351(\mathrm{k})$ & $3 / 6 / 15$ & $9 / 3 / 15$ & $15 \%$ decrease \\
\hline Inflectra (infliximab-dyyb) & Remicade (infliximab) & $35 \mathrm{l}(\mathrm{k})$ & $4 / 5 / 16$ & $11 / 21 / 16$ & $18.9 \%$ decrease \\
\hline Renflexis (infliximab-abda) & Remicade (infliximab) & $351(\mathrm{k})$ & $3 / 21 / 17$ & Possible & TBD \\
\hline Erelzi (etanercept-szzs) & Enbrel (etanercept) & $351(\mathrm{k})$ & $8 / 30 / 16$ & Q1 2019a & TBD \\
\hline Amjevita (adalimumab-atto) & Humira (adalimumab) & $351(\mathrm{k})$ & 9/23/16 & Q1 2023a & TBD \\
\hline Follow-on Biologics & \multicolumn{5}{|l|}{ Model Product } \\
\hline Omnitrope (somatropin) & Genotropin (somatropin) & $505(b)(2)$ & $5 / 30 / 06$ & $1 / 1 / 07$ & $65 \%$ decrease \\
\hline Basaglar Kwikpen (insulin glargine) & Lantus Solostar (insulin glargine) & $505(b)(2)$ & $8 / 18 / 14$ & $12 / 15 / 16$ & $15 \%$ decrease \\
\hline New Application & \multicolumn{5}{|l|}{ Model Product } \\
\hline Granix 300 mcg (tbo-filgrastim) & Neupogen (filgrastim) & $351(a)$ & $8 / 29 / 12$ & $11 / 11 / 13$ & $23 \%$ decrease \\
\hline
\end{tabular}

Note: Pricing information was obtained from RED BOOK Online, June 30, 2017.20

a Dependent on patent litigation.

$A W P=$ acquisition wholesale price; $T B D=$ to be determined

\section{Considerations by Product Channel}

\section{Inpatient, Outpatient, and Provider-Based Administration}

All of the nuances and complexities of the biosimilar approval pathway affect biosimilar acceptance and uptake in clinical settings. From the inpatient or hospital pharmacy perspective, medications are reviewed by a pharmacy and therapeutics (P\&T) committee and added to formulary on a case-by-case basis. Cost is a major driver for products considered clinically similar. Generally, 1 product within a therapeutic category would be available, and all orders for medications within that therapeutic category would be auto substituted for the formulary product for inpatient administration. Most inpatient hospitalizations are reimbursed in bundled payments, so it is in the institution's best interest to select the most clinically efficacious product at the best price.

From the outpatient pharmacy perspective, there are no formulary committees. For a community pharmacy or hospitalaffiliated discharge pharmacy, product use is driven by the pharmacy benefit associated with the patient's health plan. Outpatient pharmacies negotiate reimbursement and dispensing fees with the pharmacy benefit manager to be included in its network. Pharmacies work with the patient's pharmacy benefit formulary and utilization management strategies, and because of differences in benefit design and formularies, outpatient pharmacies are able to stock all available products. Since biosimilar products are not interchangeable, a pharmacy benefit decision to prefer a biosimilar product does not lead to an automatic substitution at the pharmacy, which would be the case with a generic small molecule product, where generic substitution by a pharmacist is typically allowed in some states. This, however, is not the case for biologic products. Therefore, the pharmacy would be responsible for notifying the prescriber and obtaining a new prescription for the biosimilar product, if the original prescription is written for the branded reference product.
For provider-based administration at independent physician office practices and hospital-based infusion centers, there is often no formulary committee governing product selection at a site level. Product use in these settings is subject to the pharmacy or medical benefit provided by patients' health plans, which have their own P\&T committees. However, independent physician office practices not affiliated with a hospital typically operate under a buy and bill model to purchase medications that are administered on-site. Independent physician office practices will often purchase product from a distributor, whereas clinics affiliated with a health system access product via the hospital pharmacy contract with a wholesaler.

Regardless of the site of administration, a benefit investigation is routinely performed before the administration of a product to understand financial implications to the patient. This process is intended to protect the patient from paying for high-cost nonpreferred therapies. However, the economic picture is different for product being administered at independent physician office practices that are not affiliated with a health system. These providers are writing prescriptions in addition to purchasing their own product and could theoretically benefit from class of trade discounts based on use. As a result, the physician offices would be acutely aware of acquisition cost and reimbursement and would arguably favor the most clinically efficacious product with the greatest margin. In other words, there could be financial incentive to continue using the branded product with a higher list price as a result of these discounts. In the current landscape of limited competition, selecting a biosimilar product as the preferred agent could increase the acquisition cost to providers and decrease the reimbursement, which then could impede provider buy-in.

\section{Response from Prescribing Community}

Overall, the response we have experienced from the prescribing community on biosimilar products has been mixed. Filgrastim 
biosimilar products have had better acceptance and use, which is likely because these agents are used for supportive care and have a clearly measurable endpoint. Infliximab biosimilar products, on the other hand, have not been as widely used and have received concerns voiced by providers. Providers are on board with infliximab biosimilars conceptually but want to see more evidence regarding switching between reference biologics and biosimilar products, especially as more products come to market. There is a perceived risk of antibody formation associated with switching between reference biologics and biosimilars, despite available evidence to the contrary. ${ }^{24}$

Our hypothesis is that a larger price difference would drive higher acceptance rate. However, medication administration and delivery methods may be equally as important as reduced costs. Unique medication delivery methods could also rival biosimilar use, as on-body delivery devices for filgrastim and products formulated for subcutaneous administration, such as rituximab, become available and potentially more convenient for patients.

\section{How We Position Biosimilars}

In April 2015, our health system-owned third-party administrator, with a fully insured business, published a policy to address biosimilars before they were released to the marketplace. The intent of the policy was to provide coverage guidelines for medications and products that the FDA had determined were therapeutically equivalent as a generic or biosimilar. The goal of this policy was to remove any roadblocks that prevent the adoption of biosimilars. As a result, the 2 approved biosimilar products were added to formulary, and incentives were put in place for patients and providers who used these products. At a high level, pharmacy and medical benefits are designed such that use of the preferred product results in greater reimbursement for providers and less cost for the patient, reducing overall costs to the health care system. When plans favor expensive brand biologics, patients could pay more money out of pocket, especially in a health savings or high deductible plan environment.

\section{Final Considerations}

The lack of an interchangeable designation adds a layer of complexity to the prescribing of biosimilar products. Shifting focus away from the concept of interchangeability and towards therapeutic equivalence will be the key to positioning biosimilar products for success. One challenge biosimilars have faced to date is that the 2 approved products are not exclusively dispensed through the pharmacy benefit at an outpatient pharmacy. These products are associated with provider-based administration where the economics are different. What must not be forgotten from this equation is that patient responsibility for cost of therapy is dependent on benefit design, and the most beneficial economic picture on the provider side might not be the same for the patient. It is also important to acknowledge that a lot is at stake with any new product (or business). If the first few biosimilars do not provide expected clinical results, they could harm the industry moving forward. Finally, with limited competition in the marketplace, we have not seen the big price decreases that were experienced with small molecule generics, but we are expecting to realize additional savings as more products become available.

\section{Authors}

JESSE PETERSON, PharmD, MS; HOLLY BUDLONG, PharmD, PhD; TIM AFFELDT, PharmD; KYLE SKIERMONT, PharmD; and GREGG KYLLO, MS, RPh, Fairview Pharmacy Services, Minneapolis, Minnesota. AL HEATON, PharmD, PreferredOne, Golden Valley, Minnesota.

AUTHOR CORRESPONDENCE: Jesse Peterson, PharmD, MS, Fairview Pharmacy Services, 711 Kasota Ave., Minneapolis, MN 55414. Tel.: 612.672.5215; E-mail: jpeter73@fairview.org.

\section{DISCLOSURES}

No outside funding supported this work. Affeldt reports advisory board membership with Janssen, and Skiermont reports membership with Amgen and McKesson. The other authors have nothing to disclose.

Peterson and Budlong contributed the study concept and design and wrote the manuscript. Affeldt, Skiermont, Kyllo, and Heaton reviewed and revised the manuscript.

\section{REFERENCES}

1. U.S. Food and Drug Administration. Information for consumers (biosimilars). August 27, 2015. Available at: http://www.fda.gov/drugs/developmentapprovalprocess/howdrugsaredevelopedandapproved/approvalapplications/ therapeuticbiologicapplications/biosimilars/ucm241718.htm. Accessed October 18, 2017

2. EuropaBio. Guide on biosimilars in Europe: when science meets policy 2014. Available at: http://www.fdanews.com/ext/resources/files/1014/10-14-EuropaBio-Guide.pdf?1494374629. October 31, 2017.

3. Patel, PK. Biologics and biosimilars. J Dermatological Treatment. 2015;26(4):299-302

4. State of Minnesota, Office of the Revisor of Statutes. 2017 Minnesota Statutes. 151.21 Substitution. Available at: https://www.revisor.mn.gov/ statutes/?id=151.21. Accessed October 18, 2017

5. U.S. Food and Drug Administration. How drugs are developed and approved. 2015. Available at: http://www.fda.gov/drugs/developmentapprovalprocess/howdrugsaredevelopedandapproved. Accessed October 18, 2017.

6. U.S. Food and Drug Administration. Therapeutic Biologic Applications (BLA). 2017. Available at: http://www.fda.gov/drugs/developmentapprovalprocess/howdrugsaredevelopedandapproved/approvalapplications/therapeuticbiologicapplications/. Accessed October 18, 2017.

7. McCamish M, Woollett G. The state of the art in the development of biosimilars. Clin Pharmacol Ther. 2012;91(3):405-17.

8. U.S. Food and Drug Administration. FDA approves Basaglar, the first "follow-on" insulin glargine product to treat diabetes. News release. December 16, 2015. Available at: http://www.fda.gov/NewsEvents/Newsroom/

PressAnnouncements/ucm477734.htm. Accessed October 18, 2017. 
9. U.S. Food and Drug Administration. FDA approval package for Omnitrope. 2010. Available at: http://www.accessdata.fda.gov/drugsatfda_ docs/nda/2010/021426Origls008.pdf. Accessed October 18, 2017.

10. U.S. Food and Drug Administration. FDA approval package for Granix. Available at: https://www.accessdata.fda.gov/drugsatfda_docs/ nda/2012/125294Origls000SumR.pdf. Accessed October 18, 2017.

11. Neupogen (filgrastim) injection, for subcutaneous or intravenous use. Amgen. Revised July 2015. Available at: https://www.accessdata.fda.gov/drugsatfda_docs/label/2015/103353s5186lbl.pdf. Accessed October 18, 2017.

12. Remicade (infliximab) lyophilized concentrate for injection, for intravenous use. Janssen Biotech. 2015. Available at: https://www.remicade.com/ shared/product/remicade/prescribing-information.pdf. Accessed October 18, 2017.

13. Inflectra (infliximab-dyyb) for injection, for intravenous use. Hospira. 2016. Available at: https://www.accessdata.fda.gov/drugsatfda_docs/ label/2016/125544s000lbl.pdf. Accessed October 18, 2017.

14. Enbrel (etanercept) solution for subcutaneous use. Amgen. 2015. Available at: https://www.accessdata.fda.gov/drugsatfda_docs/ label/2015/103795s5548lbl.pdf. Accessed October 18, 2017.

15. Humira (adalimumab) injection, for subcutaneous use. AbbVie. 2017. Available at: https://www.accessdata.fda.gov/drugsatfda_docs/ label/2017/125057s402lbl.pdf. Accessed October 31, 2017.

16. Basglar (insulin glargine injection), for subcutaneous use. Lilly USA. 2016. Available at: https://www.accessdata.fda.gov/drugsatfda_docs/ label/2016/205692s001lbl.pdf. Accessed October 18, 2017.

17. Omnitrope (somatropin) injection, for subcutaneous use. Sandoz. 2016. Available at: https://dailymed.nlm.nih.gov/dailymed/fda/fdaDrugXsl. cfm?setid=58d84ffa-4056-4e36-ad67-7bd4aef444a5\&type=display. Accessed October 18, 2017.
18. Granix (tbo-filgrastim) injection for subcutaneous use. Teva Pharmaceuticals USA. 2014. Available at: https://www.accessdata.fda.gov/ drugsatfda_docs/label/2014/125294s035lbl.pdf. Accessed October 18, 2017. 19. Zarxio (filgrastim-sndz) injection, for subcutaneous or intravenous use. Sandoz. 2015. Available at: https://www.accessdata.fda.gov/drugsatfda_docs/ label/2015/125553lbl.pdf. Accessed October 18, 2017.

20. Micromedex. RED BOOK Online. Truven Health Analytics. June 30, 2017. Available at: https://truvenhealth.com/products/micromedex/product-suites/ clinical-knowledge/red-book. Accessed October 18, 2017.

21. U.S. Food and Drug Administration. Nonproprietary naming of biological products. Guidance for industry. January 2017. Available at: http://www. fda.gov/downloads/drugs/guidancecomplianceregulatoryin-formation/guidances/ucm459987.pdf. Accessed October 18, 2016.

22. Generics and Biosimilars Initiative. Biosimilars approved in Europe. Updated October 6, 2017. Available at: http://www.gabionline.net/ Biosimilars/General/Biosimilars-approved-in-Europe. Accessed October 18, 2017.

23. Miller S. The $\$ 250$ billion potential of biosimilars. Express Scripts Lab. April 23, 2013. Available at: http://lab.express-scripts.com/lab/insights/ industry-updates/the-\$250-billion-potential-of-biosimilars. Accessed October 18, 2017

24. Jorgensen KK, Olsen IC, Goll, GL, et al. Switching from originator infliximab to biosimilar CT-P13 compared with maintained treatment with originator infliximab (NOR-SWITCH): a 52-week, randomized, doubleblind, non-inferiority trial. Lancet. 2017;389(10086):2304-16.

25. QuintilesIMS. Biosimilars by region: United States. Regulatory guidelines in the United States. 2016. Available at: http://www.quintiles.com/ microsites/biosimilars-knowledge-connect/biosimilars-by-region/usa. Accessed October 28, 2017. 